without any coagulant. The serum separates out well in twentyfour hours.

Two c.c. of the serum are transferred to a centrifuge tube, and to it are added 2 c.c. distilled water, a few drops of 2 per cent. ammonia, and 1 c.c. of a saturated solution of ammonium oxalate. The contents are thoroughly mixed by rotation and set aside for at least 45 minutes. The tube and its contents are next centrifuged at 2,000 revolutions for three minutes. This results in the calcium oxalate produced in the above reactions being closely and firmly packed at the bottom of the tube. The supernatant fluid is carefully poured off and the tube allowed to drain by inverting it over dry filter paper for five minutes. Two c.c. of 2 per cent. ammonia are now added and the tube again centrifuged and drained as before. Two c.c. of normal sulphuric acid are now added and the tube placed in a beaker of water is now heated to about $80^{\circ}$ Cent. The contents are then titrated with $\mathrm{N} / 100$ potassium permanganate solution in a micro-burette till a faint pink tinge is left. The solution must be freshly prepared for each new set of estimations. One c.c. of $\mathrm{N} / 100$ solution of potassium permanganate corresponds to $10 \mathrm{mg}$. of calcium.

\title{
A CASE OF SYMPATHETIC INFLAMMATION ASSOCIATED WITH INTRAOCULAR SARCOMA
}

BY

\author{
T. HARrison ButLer \\ BIRMINGHAM \\ with a pathological note by \\ J. JAMESON Evans \\ BIRMINGHAM
}

CASES of sympathetic inflammation following an intraocular sarcoma in the fellow eye have been reported by Fuchs, Meller, and others, but must be of extreme rarity. The following example of this complication seems therefore worthy of record.

Miss H., aged 20 years, came to the Coventry Hospital on December 8, 1924, and was found to be suffering from severe irido-cyclitis in both eyes. She gave the history that the right eye had been inflamed for five weeks, the left for six weeks. She was quite positive that the left eye began to give trouble before the right. A month previously she had facial paralysis on the left side but this had completely disappeared when she was first seen. There was no history of any headache or vomiting. There had been slight 
vertigo but no tinnitus. She had been slightly deaf for as long as she could remember. Three years ago her tonsils and adenoids were removed. She had been treated by her doctor with large doses of iodide of potassium. The mother suffers from myxoedema but has no symptoms or signs of syphilis.

Condition when first seen.-V.R. Fingers at one foot, not improved with glasses. V.L. 1/60. Not improved.

Both eyes show ciliary injection, the irides are muddy, and there are several posterior synechiae. The posterior surfaces of both corneae are thickly covered with "mutton-fat" precipitates. The tension is normal. The right eye is painful and both are tender. The Wassermann reaction is strongly positive. The general appearance of the patient is healthy, and there is nothing to suggest syphilis, but because of the positive Wassermann reaction the patient was sent to the venereal department, and received a course of injections with novo-arsenobillon and was treated with mercury. She was ordered atropine drops and hot applications.

June 15, 1926. The patient has not been seen in the eye department for eighteen months and has never used her atropine. There is now a complete annular synechia with iris bombé on each side and the tension is raised. No precipitates.

July 1, 1926. Tension; right by Schiötz tonometer, 16 ; left 13 .

September 14, 1926. V.R. corrected 6/24. V.L. light perception only.

September 30, 1926. Schiötz, tension, 36.36. Examination with the slit-lamp showed no cells in the aqueous. Chamber very shallow and iris bombé.

October 5, 1926. Gelatinous nodules seen on the pupillary margin of the left iris. Pellucid type of precipitates each eye.

October 19, 1926. Schiötz, 35 and 40.

October 26, 1926. Circum-corneal injection both eyes. Keratic precipitates.

November 1, 1926. Schiötz, 37 and 37.

November 2, 1926. Iridectomy, left eye.

November 16, 1926. Schiötz, 44 and 6 . The vision of the left eye has improved. Large hyphaema, which is gradually absorbing.

November 22, 1926. Iridectomy, right eye.

December 7, 1926. Schiötz, 7 and 12.

December 23, 1926. Hyphaema right eye, that in the left has disappeared. Lenticular opacity both eyes, no red reflex seen. V.R., 1/60 V.L., hand reflex.

January 4,1927 . No hyphaema. The crypts in left iris are greatly enlarged and are seen with the slit-lamp to be filled with a gelatinous material, in fact the whole of the deeper mesenteric layer appears to 
be changed into this type of tissue. The coloboma has closed up leaving a small drawn up pupil.

The Wassermann reaction is negative.

February 22, 1927. The left eye, being hard and very painful, was removed. On section a white disc-shaped tumour was seen at the posterior pole measuring six millimetres in diameter. This was cut by Dr. Wright, pathologist to the Coventry Hospital, and he reported that it was a sarcoma.

\section{Pathological Note by J. Jameson Evans}

Cornea.-Transparent with pericorneal engorgement and some peripheral oedema of the corneal stroma.

Endothelium intact but shows blood cells in the region of the corneo-iridic angle. Spaces of Fontana crowded with blood cells and inflammatory cells.

Iris.-Vessels congested, infiltration of stroma with round cells, chiefly polymorphs. Patch of pigmented uveal cells deposited on the anterior surface of the iris. Pigmented epithelium swollen and desquamating.

Ciliary body.-Congested vessels. Depigmentation and desquamation of epithelium, Some blood round pigmented cells and in the fibres of the suspensory ligament.

Retina.-Vessels engorged. Some haemorrhages and oedema. Detachment in region of the ora serrata. Pigment epithelium depigmented over the major portion of the fundus, and detached by an albuminous exudate in the equatorial region.

Choroid.- Intense venous congestion with some cellularinfiltration, not lymphocytic, in posterior region up to the equator.

Sessile growth.-At the posterior pole consisting of mixed cells deeply pigmented, and largely spindle-shaped. Some haemorrhages. No evidence of perforation of the sclera.

Further history.-The removal of the left eye was followed by a gradual but very definite improvement in the condition of the right eye. The globe lost its injection and no pain was experienced. The deposit of precipitates diminished and apparently no new ones formed. Vision was very poor, the patient could get about in her own home but not out of doors. The coloboma was drawn together and filled with an organized exudate. In November, 1926, the eye again became painful and it was found that the tension had risen to 50 Schiötz units. On November 16, 1926, a large iridectomy was made horizontally outwards. This was followed by considerable haemorrhage which rapidly absorbed. This operation was most 
satisfactory in its effects. There was no inflammatory reaction and the coloboma remained free from exudate. The tension sank to normal and the patient was able to count fingers and to get about well even in places that she did not know.

Comments. - The presence of an intraocular growth was not suspected until the eye was bisected. There would seem to be little doubt that the severe irido-cyclitis was due to toxins liberated by the necrosing action of the sarcoma. The rapid improvement which took place in the sympathizing eye after the removal of the exciting eye strongly supports the idea that the inflammation was sympathetic in type. On the other hand the true Fuchs inflammation was not present nor were there any cells in the aqueous of either eye. It is obvious, therefore, that the case was not one of true sympathetic ophthalmitis, although it was a sympathetic inflammation.

The eye eventually became perfectly white, and the astonishing acuity of $6 / 12$ was gained. The patient has now returned to her work as an assistant in a draper's shop.

\section{CASE OF EMPHYSEMA OF THE CONJUNCTIVA}

BY

LaURa M. LigerTwood, F.R.C.S.E.

CLINICAL TUTOR, EYE DEPARTMENT, ROYAL INFIRMARY, EDINBURGH

THE following accident is of such unusual occurrence as to merit special attention,

On June 5, 1926, W.B., male, aged 40 years, reported at the Eye Department of the Royal Infirmary, Edinburgh, and gave the following history.

Patient stated that he was employed as an engraver in a granite yard and that he worked with a pneumatic driller. The air which drives these pneumatic drills is compressed by an engine, led through the yard in large iron pipes and smaller rubber tubes and when emerging from the nozzle of the tube has a pressure of $70 \mathrm{lbs}$. per square inch. It is the custom of the men when they have finished work to blow the dust out of their clothes by means of the compressed air. On the date in question, W.B. took hold of the flexible rubber tube about two feet from its free end and turned on the air, the pressure of which caused the tube to fly backward and pass in close proximity to the face actually touching the skin over the right maxilla. The eye received the full force of the $70 \mathrm{lbs}$. pressure. 